\title{
\begin{tabular}{l|l} 
Mibraries & DSpace@MIT
\end{tabular}
}

\author{
MIT Open Access Articles
}

Foreword to the Special Issue on the 2008 International Geoscience and Remote Sensing Symposium (IGARSS '08)

The MIT Faculty has made this article openly available. Please share how this access benefits you. Your story matters.

Citation: Entekhabi, D. et al. "Foreword to the Special Issue on the 2008 International Geoscience and Remote Sensing Symposium (IGARSS'08)." Geoscience and Remote Sensing, IEEE Transactions on 47.11 (2009): 3595-3597. (C) 2009 IEEE

As Published: http://dx.doi.org/10.1109/tgrs.2009.2032825

Publisher: Institute of Electrical and Electronics Engineers

Persistent URL: http://hdl.handle.net/1721.1/52408

Version: Final published version: final published article, as it appeared in a journal, conference proceedings, or other formally published context

Terms of Use: Article is made available in accordance with the publisher's policy and may be subject to US copyright law. Please refer to the publisher's site for terms of use. 


\section{Foreword to the Special Issue on the 2008 International Geoscience and Remote Sensing Symposium (IGARSS'08)}

$\mathbf{T}$ HE 2008 International Geoscience and Remote Sensing Symposium (IGARSS'08) was held from July 6 to 11 at the Hynes Convention Center in Boston, MA. The General Co-Chairs were Prof. John Kerekes of the Rochester Institute of Technology and Prof. Eric Miller of Tufts University. The Technical Program Co-Chairs were Prof. Dara Entekhabi of the Massachusetts Institute of Technology and Prof. Steven Reising of Colorado State University.

The theme of IGARSS'08 was "Geoscience and Remote Sensing: The Next Generation." For this year's symposium, the Call for Papers topic list was substantially streamlined to a compact list of 39 choices in nine theme areas. Consistent with the previous few IGARSS, this year's symposium attracted nearly 2400 abstract submissions. In order to maintain a highquality technical program, more than 30 dedicated experts on the Technical Program Committee assigned the submitted abstracts to 1607 reviewers who completed an average of 3.4 reviews per contributed abstract, a record level of participation in the review process.

The Technical Program Committee, which included 45 theme coordinators/session organizers and 109 invited session organizers, met in Atlanta, GA, on February 29 to organize 1885 accepted presentations into 211 oral half sessions of five papers each and 99 interactive sessions of up to 12 posters each. The technical program covered the key theme areas of geoscience, including the studies of land, oceans, atmosphere, and cryosphere, as well as the full extent of remote sensing topics, from electromagnetic modeling, radiative transfer, design of sensors and missions, and advanced image/signal analysis techniques to applications, education, and policy. A new element of the IGARSS technical program was the organization of four timely highly relevant panel discussions on areas in which remote sensing has an increasing impact on society: numerical weather prediction, NASA missions arising from the National Research Council Decadal Survey, human and environmental health, and baseline climate identification and global change. In addition, a special poster session on the remote sensing analysis of recent natural disasters was organized by Prof. Melba Crawford during the month prior to the meeting. We would like to thank the 1607 reviewers, the invited session organizers, and the theme coordinators/session organizers for their generous support in assembling a top-quality technical program.

Consistent with the theme of the next generation in geoscience and remote sensing, new student activities were initiated at IGARSS'08, including a career forum featuring five

Digital Object Identifier 10.1109/TGRS.2009.2032825 industrial employers meeting with dozens of interested students in remote sensing and a young professionals' luncheon during which more than 50 students received career advice from experienced professionals. Finally, extensive outreach to precollege students in the Boston area included outreach exhibits, a guided tour of the Boston Science Museum, and related activities.

The participation in IGARSS'08 was at a record level, demonstrating the growing recognition and prestige of the symposium and benefiting from the attractive Boston venue. Technical registration numbered 1721, while the total number of attendees, including accompanying persons, exhibitors, local precollege students and workshop participants, was 2071. This level of participation and the attractive location helped to lower the no-show rate to $5 \%$ and $20 \%$ in oral and poster sessions, respectively.

For this Special Issue, 61 manuscripts were submitted, and after the regular rigorous review process of the IEEE Transactions on Geoscience and Remote Sensing, a total of 29 was accepted for publication in this Special Issue. We would like to thank all reviewers for their time and dedication to this task.

Finally, special thanks are due to Prof. Christopher Ruf (Editor-in-Chief), Ms. Alison Larkin, Ms. Christine Kurzawa, and Mr. George Criscione for their continuous and patient assistance during the preparation of this Special Issue.

DARA Entekhabi, Guest Editor

Ralph M. Parsons Laboratory for Environmental

Science and Engineering, Civil and Environmental Engineering and Earth, and Atmosphere and

Planetary Sciences Departments

Massachusetts Institute of Technology

Cambridge, MA 02139 USA

JoHn P. KeREKES, Guest Editor

Chester F. Carlson Center for Imaging Science

Rochester Institute of Technology

Rochester, NY 14623 USA

ERIC L. Miller, Guest Editor

Lab for Imaging Science Research

Electrical and Computer Engineering Department

Tufts University

Medford, MA 02155 USA

Steven C. Reising, Guest Editor

Microwave Systems Laboratory

Electrical and Computer Engineering Department

Colorado State University

Fort Collins, CO 80523 USA 


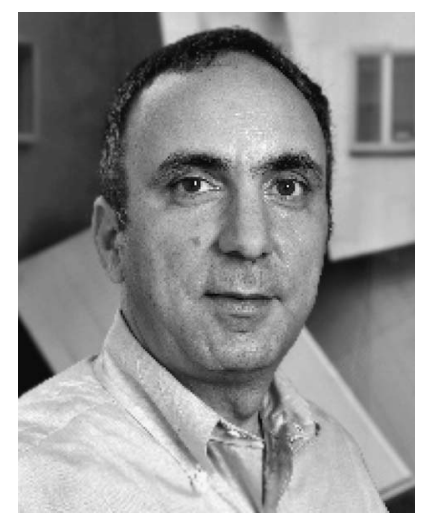

Dara Entekhabi (M'00-SM'04) received the Ph.D. degree from the Massachusetts Institute of Technology (MIT), Cambridge, in 1990.

He is currently a Professor with the Department of Civil and Environmental Engineering, MIT. He serves as the Director of the MIT Ralph M. Parsons Laboratory for Environmental Science and Engineering, as well as the MIT Earth System Initiative. He is the Science Team Leader of the NASA Soil Moisture Active and Passive satellite mission ready for launch in 2014. His research activities are in terrestrial remote sensing, data assimilation, and coupled land-atmosphere system behavior.

Dr. Entekhabi is a Fellow of the American Meteorological Society and the American Geophysical Union. He served as the Technical Program Co-Chair of IGARSS 2008.

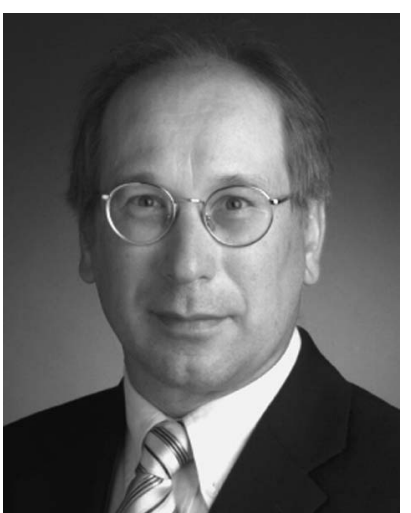

John P. Kerekes (S'81-M'89-SM'00) received the B.S., M.S., and Ph.D. degrees in electrical engineering from Purdue University, West Lafayette, IN, in 1983, 1986, and 1989, respectively.

From 1983 to 1984, he was a member of the Technical Staff with the Space and Communications Group, Hughes Aircraft Company, El Segundo, CA, where he performed circuit design for communications satellites. From 1986 to 1989, he was a Graduate Research Assistant with the School of Electrical Engineering and the Laboratory for Applications of Remote Sensing, Purdue University. From 1989 to 2004, he was a Technical Staff Member with the Lincoln Laboratory, Massachusetts Institute of Technology, Lexington. Since 2004, he has been an Associate Professor with the Chester F. Carlson Center for Imaging Science, Rochester Institute of Technology, Rochester, NY. His research interests include the modeling and analysis of remote sensing system performance in pattern recognition and geophysical parameter retrieval applications.

Dr. Kerekes is a member of Tau Beta Phi, Eta Kappa Nu, the American Geophysical Union, the American Society for Photogrammetry and Remote Sensing, the Optical Society of America, and the Society of Photo-Optical Instrumentation Engineers. From 1995 to 2004, he served as the Chair of the Boston Section Chapter of the IEEE Geoscience and Remote Sensing Society (GRSS). He is currently serving as the Founding Chair of the Western New York Chapter of GRSS, as well as an Associate Editor for both the IEEE TRANSACTIONS ON GEOSCIENCE AND REMOTE SENSING and the IEEE Transactions on Image Processing. He was the General Co-Chair of the 2008 IEEE International Geoscience and Remote Sensing Symposium held in Boston, MA.

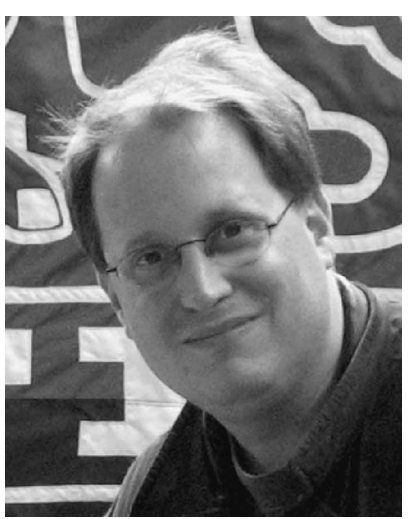

Eric L. Miller (S'90-M'95-SM'03) received the S.B., S.M., and Ph.D. degrees in electrical engineering and computer science from the Massachusetts Institute of Technology, Cambridge, in 1990, 1992, and 1994, respectively.

He is currently a Professor with the Department of Electrical and Computer Engineering and an Adjunct Professor of computer science with Tufts University, Medford, MA. Since September 2009, he has been the Associate Dean of research for Tufts' School of Engineering. His research interests include physics-based tomographic image formation and object characterization, inverse problems in general and inverse scattering in particular, regularization, statistical signal and imaging processing, and computational physical modeling. This work has been carried out in the context of applications including medical imaging, nondestructive evaluation, environmental monitoring and remediation, land mine and unexploded ordnance remediation, and automatic target detection and classification.

Dr. Miller is a member of Tau Beta Pi, Phi Beta Kappa, and Eta Kappa Nu. He received the CAREER Award from the National Science Foundation in 1996 and the Outstanding Research Award from the College of Engineering, Northeastern University, Boston, MA, in 2002. He is currently serving as an Associate Editor for the IEEE Transactions on GeOSCIEnCE AND REMOte SENSING and was in the same position at the IEEE TRANSACTIONS ON IMAGE PRoCESSING from 1998 to 2002. He was the General Co-Chair of the 2008 IEEE International Geoscience and Remote Sensing Symposium held in Boston. 


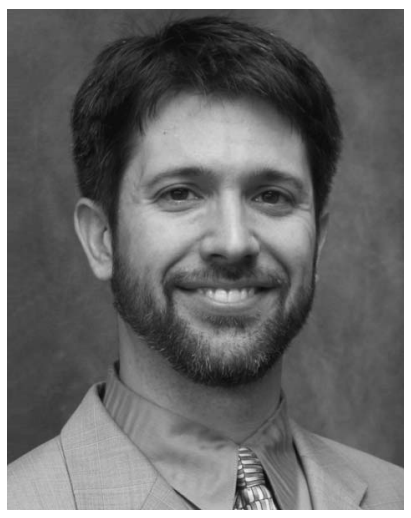

Steven C. Reising (S'88-M'98-SM'04) received the B.S.E.E. (magna cum laude) and M.S.E.E. degrees in electrical engineering from the Washington University in St. Louis, St. Louis, MO, and the Ph.D. degree in electrical engineering from Stanford University, Stanford, CA, in 1998, where he was supported by a NASA Earth Systems Science Fellowship and advised by Prof. Umran S. Inan.

He is currently an Associate Professor of electrical and computer engineering with Colorado State University (CSU), Fort Collins. Shortly before joining the CSU faculty in 2004, he received tenure from the University of Massachusetts, Amherst, where he has been an Assistant Professor of electrical and computer engineering since 1998. At Stanford, his research focused on lowfrequency remote sensing of lightning and its energetic coupling to the ionosphere, which produces chemical changes and transient optical emissions. During the summers of 1999, 2000, and 2003, he was a Summer Faculty Fellow with the Remote Sensing Division, Naval Research Laboratory (NRL), Washington, DC. His research interests span a broad range of remote sensing disciplines, including passive microwave and millimeter-wave remote sensing of the oceans, atmosphere, and land; microwave circuits and radiometer systems; lidar systems for sensing of temperature and winds in the middle and upper atmosphere; and atmospheric electrodynamics. He is the Principal Investigator of ten grants from the National Science Foundation (NSF), National Aeronautics and Space Administration, Office of Naval Research (ONR), NRL (subcontract from the National Polar-orbiting Operational Environmental Satellite System Integrated Program Office), the University of Rome, Rome, Italy, (subcontract from the European Space Agency), and Ball Aerospace \& Technologies Corp. He has served as a Reviewer for the Journal of Atmospheric and Oceanic Technology, and the Journal of Oceanography, Radio Science, and Geophysical Research Letters.

Dr. Reising received the NSF CAREER Award (in 2003-2008) in the areas of physical and mesoscale dynamic meteorology, and the ONR Young Investigator Program Award (in 2000-2003) for passive microwave remote sensing of the oceans. He was awarded the Barbara H. and Joseph I. Goldstein Outstanding Junior Faculty Award in 2004, the Lilly Teaching Fellowship for 2001-2002, and a Young Scientist Award at the International Union of Radio Science (URSI) General Assembly in Toronto, ON, Canada, in 1999. While at Stanford, he received the first place award in the U.S. National Committee (USNC)/URSI Student Paper Competition at the 1998 National Radio Science Meeting in Boulder, CO. He currently serves as the Vice President of Technical Activities of the IEEE Geoscience and Remote Sensing Society (GRSS). He has been serving as an elected member of the IEEE GRSS Administrative Committee continuously since 2003, after three-year terms as the Editor of the GRSS Newsletter (in 2000-2002) and an Associate Editor for the University Profiles (in 1998-2000). He has been an Associate Editor of the IEEE Geoscience and Remote Sensing Letters (GRSL) since its founding in 2004. He has been a Guest Editor of the IEEE Transactions on Geoscience and Remote Sensing (TGARS) for the International Geoscience and Remote Sensing Symposium (IGARSS) 2008 Special Issue published in November 2009 and the Special Issue on Microwave Radiometry and Remote Sensing Applications published in July 2007. He has served as a Reviewer for TGARS, GRSL, and the IEEE Transactions on MicrowaVe Theory and TEChNiQues.

He serves the URSI as the Secretary and Chair-Elect of its USNC, consisting of ten scientific commissions in applied electromagnetics. Previously, he chaired its annual Student Paper Prize Competition at each National Radio Science Meeting in Boulder from 2004 to 2008 and at the URSI North American Radio Science Meeting in Ottawa, ON, Canada, in 2007. He chaired the first URSI International Student Paper Prize Competition at the URSI General Assembly in Chicago, IL in August 2008. In addition, he will Co-Chair the Technical Program Committee for the 2010 URSI National Radio Science Meeting to be held in Boulder. He served as the Secretary of USNC-URSI Commission F (in 2006-2008) and is a member of URSI Commissions F, G, and $\mathrm{H}$, the American Meteorological Society, the American Geophysical Union, Tau Beta Pi, and Eta Kappa Nu. In organizing scientific meetings, he was one of two Technical Program Co-Chairs of the IEEE IGARSS 2008 in Boston, MA, with over 1700 attendees. He served as the General Chair of MicroRad'06, the 9th Specialist Meeting on Microwave Radiometry, held in March 2006 in San Juan, Puerto Rico, with 126 attendees from 15 countries. He was the Local Arrangement Chair for IGARSS 2006 in Denver, CO, with over 1250 attendees. He has been an active participant in each IGARSS Technical Program Committee since 2001 . 